Pendas : Jurnal IImiah Pendidikan Dasar, ISSN Cetak : 2477-2143 ISSN Online : 2548-6950 Volume VI Nomor 01, Juni 2021

\title{
PEMANFAATAN MODUL TEMATIK SEBAGAI ALAT EVALUASI PEMBELAJARAN PADA SAAT PANDEMI COVID-19
}

\author{
Arif Mishbah Suryawanto ${ }^{1}$, Wahyu Lestari² \\ 1,2Pendidikan Dasar, Pascasarjana, Universitas Negeri Semarang \\ 1arifmishbah@students.unnes.ac.id, 2wahyupyarlestari@mail.unnes.ac.id
}

\begin{abstract}
During distance learning due to the Covid-19 pandemic, learning evaluation must still be carried out. There are many ways and evaluation tools that teachers can use in carrying out learning evaluations. One of them is the thematic learning module. This is because the module does not only contain learning materials, but there are learning evaluation materials in it. This study aims to determine the use of thematic modules as a learning evaluation tool. This study used descriptive qualitative method. The data collection technique in this research is by interviewing several teachers in elementary schools in Bandung. The results of the research based on the results of the interviews show that at this time learning is carried out remotely, teachers really need modules, because modules are needed as interesting teaching materials and help students understand learning material. Furthermore, at this time, the module is often used by teachers in distance learning, apart from being an additional teaching material, the module is also used as a learning evaluation tool. Because according to the teacher, the modules in it not only contain learning material, but there are also evaluation questions. The conclusion that can be obtained is that teachers really need modules when learning takes place, especially when learning is carried out remotely, because it is hoped that using thematic modules will help students learn independently and understand learning material, as well as the results of evaluating student learning outcomes through modules can be achieved properly.
\end{abstract}

Keywords: thematic modules, distance learning, covid-19 pandemic, learning evaluation, evaluation tools

\section{ABSTRAK}

Pada saat pembelajaran secara jarak jauh dikarenakan pandemi covid-19 evaluasi pembelajaran harus tetap dilaksanakan. Banyak cara dan alat evaluasi yang dapat digunakan guru dalam melaksanakan evaluasi pembelajaran. Salah satunya adalah modul pembelajaran tematik. Dikarenakan modul tidak hanya berisi bahan ajar materi pembelajaran saja, tetapi terdapat bahan evaluasi pembelajaran di dalamnya. Penelitian ini bertujuan untuk mengetahui pemanfaatan modul tematik sebagai alat evaluasi pembelajaran. Penelitian ini menggunakan metode deskriptif kualitatif. Teknik pengumpulan data pada penelitian ini adalah dengan wawancara kepada beberapa guru di sekolah dasar di Kota Bandung. Hasil penelitian berdasarkan hasil wawancara menunjukkan, pada saat ini pembelajaran dilaksanakan secara jarak jauh, guru sangat memerlukan modul, dikarenakan modul diperlukan sebagai bahan ajar yang menarik dan membantu siswa memahami materi pembelajaran. Selanjutnya pada saat ini, modul sering digunakan guru dalam pembelajaran jarak jauh, selain sebagai tambahan bahan 
ajar, modul digunakan juga sebagai alat evaluasi pembelajaran. Karena menurut guru, modul didalamnya bukan hanya terdapat materi pembelajaran, tetapi terdapat juga soal-soal evaluasi. Simpulan yang dapat diperoleh yaitu guru sangat membutuhkan modul saat pembelajaran berlangsung, terutama saat pembelajaran dilaksanakan secara jarak jauh, karena diharapkan dengan menggunakan modul tematik, akan membantu siswa dalam belajar secara mandiri dan memahami materi pembelajaran, serta hasil evaluasi hasil belajar siswa melalui modul dapat tercapai dengan baik.

Kata Kunci: Modul Tematik, Pembelajaran Jarak Jauh, Pandemi Covid-19, Evaluasi Pembelajaran, Alat Evaluasi.

\section{A. Pendahuluan}

Pembelajaran

merupakan

interaksi antara guru dan siswa dalam rangka mencapai tujuan yang telah ditentukan. Pembelajaran adalah hubungan antara guru dan siswa yang tujuannya adalah menggapai tujuan yang telah direncanakan. Selain itu, pembelajaran yang biasanya menghubungkan semua aspek, mulai dari pendidik hingga siswa dan persiapan administratif. Untuk mencapai tujuan tersebut, evaluasi pembelajaran harus dilakukan. Evaluasi pembelajaran merupakan suatu kegiatan atau proses yang digunakan untuk mengetahui sejauh mana suatu kegiatan telah mencapai tujuan yang telah ditentukan, atau dapat diartikan sebagai Tindakan atau proses untuk menentukan nilai-nilai dari hal-hal yang berkaitan dengan kegiatan belajar tersebut. Evaluasi biasanya dilakukan dengan cara penilaian.
Guru biasanya menggunakan alat tes dan non tes untuk menilai pengetahuan, sikap dan keterampilan siswa. Fuadi, Sumaryanto, Lestari, W. (2015) mengemukakan bahwa penilaian harus selalu dilakukan oleh guru, dan kemampuan guru dalam melakukan penilaian harus menjadi prioritas dalam peningkatan mutu Pendidikan. Menilai apakah dilaksanakan dengan benar dan tepat, serta dapat menghasilkan data dan informasi yang akurat tentang tingkat pencapaian hasil belajar siswa dan kualitas proses pembelajaran. Selain itu menurut Kisno, Turmudi, Nia (dalam Nugroho et al., 2020) asesmen merupakan bagian yang penting sekali dalam pembelajaran, dan berperan penting dalam memahami bagaimana guru mengajarkan sesuatu dan apa yang akan diperoleh siswa setelah mempelajari sesuatu. Hal ini dapat memberikan informasi 
Pendas : Jurnal Ilmiah Pendidikan Dasar, ISSN Cetak : 2477-2143 ISSN Online : 2548-6950 Volume VI Nomor 01, Juni 2021

tentang pemahaman, kelemahan dan kelebihan siswa.

Seperti yang kita ketahui, kurikulum yang sekarang digunakan adalah kurikulum 2013. Khusus di sekolah dasar Kurikulum 2013 adalah kurikulum tematik integratif yang didasarkan pada tema dengan memadukan beberapa pelajaran menjadi satu tema. Kurikulum 2013 memang disiapkan dalam mencetak generasi yang siap untuk menghadapi masa depan sesuai perkembangan zaman. Pada kurikulum 2013 khususnya di sekolah dasar, pembelajaran di kelas dilaksanakan secara tematik. Pembelajaran tematik adalah salah satu jenis kerangka proses pembelajaran terpadu dengan cara menggabungkan beberapa mata pelajaran sehingga menjadi sebuah tema dan siswa dapat mendapatkan pengalaman yang bernilai dalam belajar.

Menurut Mamik (dalam Sofiyatunningtiyas, Nugroho, Muslim. 2020) mengemukakan pembelajaran tematik adalah suatu cara dari aspek pengetahuan, keterampilan dan sikap terintegrasi, serta diharapkan muncul pemikiran yang kreatif dengan menggunakan tema dari siswa. Selain itu menurut Kadir dan Asrohah (dalam
Anggraini, Mering, Fadilah 2020) Pembelajaran tematik direncanakan untuk meningkatkan hasil belajar dengan cara menarik pengalaman siswa dari ranah pengetahuan dan kehidupannya agar hasilnya optimal dan maksimal. Integrasi dalam pembelajaran, diharapkan pada diri peserta didik muncul pemahaman yang menyeluruh. Pembelajaran tematik merupakan pembelajaran yang dapat mengembangkan aspek pengetahuan, sikap dan keterampilan yang dimiliki oleh siswa sehingga merupakan pembelajaran yang utuh dan menyeluruh. Pembelajaran ini memanfaatkan tema-tema yang berkaitan dengan kehidupan siswa, maka diharapkan pembelajaran dapat bermakna bagi siswa karena berkaitan dengan kehidupan seharihari. Saat ini sedang terjadi pandemi wabah covid-19.

Adanya pandemi wabah Covid19 memang memberikan pengaruh yang sangat terasa terhadap seluruh aspek kehidupan manusia. Salahsatunya adalah Pendidikan. Pembelajaran di sekolah pada saat pandemi dilaksanakan secara jarak jauh bukan tatap muka di sekolah. Dengan ini maka menjadi tantangan bagi guru agar melaksanakan 
Pendas : Jurnal Ilmiah Pendidikan Dasar, ISSN Cetak : 2477-2143 ISSN Online : 2548-6950 Volume VI Nomor 01, Juni 2021

pembelajaran dengan siswa dapat terlaksana dengan baik, termasuk juga evaluasi. Astuti, Lestari, W. Cahyono. A (2021) menyatakan saat ini kondisi lingkungan berbeda dari sebelumnya, pembelajaran online harus tetap berjalan. Seorang guru harus tetap professional dalam menjalankan tugas yaitu mengajar dan tentunya harus siap menghadapi tantangan. Maka tugas seorang guru menjadi sangat kompleks dalam merencanakan pembelajaran agar siswa dalam belajar tetap nyaman dan paham dengan materi yang diberikan. Selain itu guru harus tetap mengajarkan pendidikan karakter kepada siswa, karena menurut (Iryanti et al., 2021) pendidikan karakter adalah cara yang paling tepat untuk diajarkan dan ditanamkan dalam penguatan kepribadian atau watak siswa

Kegiatan evaluasi pembelajaran yang didalamnya terdapat penilaian dilaksanakan secara jarak jauh juga. Menurut Mukti P.W dan Lestari, W. (2020) Evaluasi harus tetap dilaksanakan karena fungsinya sebagai penaksir dan menakar keberhasilan dari kegiatan pembelajaran, selain itu memperkirakan sejauh mana pencapaian hasil belajar siswa terhadap salah satu atau seluruh tujuan pembelajaran. Sehingga melalui kegiatan evaluasi dapat dijadikan sebagai bahan untuk mempertimbangkan melakukan perubahan dan pengembangan kualitas pembelajaran.

Banyak cara dan alat evaluasi yang bisa digunakan oleh guru untuk melaksanakan

evaluasi pembelajaran. Salah satunya adalah dengan menggunakan modul pembelajaran. (Arum \& Wahyudi, 2016) menyatakan, Modul pembelajaran adalah bahan ajar yang dibuat secara tertata dan terstruktur untuk mencapai tujuan dan keterampilan yang ingin dicapai. Modul dibuat dengan menggunakan bahasa yang mudah dimengerti oleh siswa sesuai tingkatan pemahaman siswa sesuai jenjangnya. Suatu modul harus menunjukkan kompetensi dasar yang harus digapai oleh siswa, serta ditampilkan dengan bahasa yang baik, menarik, dan lengkap dengan contoh/gambar yang membantu agar materi bisa dikuasai oleh siswa. Modul merupakan salah satu dari pengembangan dari bahan ajar. Menurut Depdiknas (dalam Anwar, Ruminiati, Saharjo 2017) 
Pendas : Jurnal Ilmiah Pendidikan Dasar, ISSN Cetak : 2477-2143 ISSN Online : 2548-6950 Volume VI Nomor 01, Juni 2021

pengembangan bahan ajar harus mencermati hal pokok pembelajaran. Salah satu contoh hal pokok dalam pembelajaran yaitu memaparkan dari yang gampang ke sukar dan konkrit ke abstrak. Modul tematik merupakan salahsatu dari pengembangan bahan ajar pembelajaran, yaitu sebagai pengembangan dari buku tematik yang selama ini dipakai sebagai bahan ajar utama. Bahan ajar adalah satu kesatuan dari berbagai macam komponen yang ada di dalam penyusunan materi pembelajaran. Prastowo (dalam Purnomo \& Wulandari, 2019) menyatakan, modul adalah bahan ajar yang tersusun dari komponen yaitu judul, petunjuk belajar, kompetensi dasar atau materi pokok, informasi pendukung, latihan, tugas atau langkah kerja, dan penilaian.

Berdasarkan

penjelasan tersebut, modul sudah memenuhi syarat sebagai bahan ajar. Riwanti \& Hidayati (2019) menyatakan, Modul diwujudkan sebagai bahan ajar karena dapat dipergunakan secara bebas oleh siswa, hal ini bertujuan untuk menanggulangi permasalahan yang ada jika pada kegiatan belajar seperti biasa, guru berhalangan untuk hadir atau melakukan pertemuan secara langsung didalam kelas. Bukan itu saja, modul dapat digunakan untuk siswa belajar mandiri di rumah, jadi siswa tidak hanya dapat memakai modul pada saat disekolah saja atau pada saat jam pelajaran saja. Arum \& Wahyudi (2016) mengemukakan modul memiliki beberapa ciri-ciri yang pertama yaitu modul harus membantu siswa belajar mandiri mandiri, yang kedua adalah materi yang tercukupi dalam kegiatan pembelajaran, yang ketiga adalah pemanfaatan modul berdiri sendiri tidak terikat atau bergantung pada media lain, dan yang keempat adalah modul yang disusun terdapat Bahasa yang digunakan sesuai dengan tingkat pemahaman siswa.

Berdasarkan hasil observasi terhadap pembelajaran jarak jauh yang sekarang dilaksanakan dikarenakan pandemi wabah covid-19 di salah satu sekolah dasar di Kota Bandung, masih terdapat guru hanya memaksimalkan pembelajaran melalui whatsapp group, bahan ajar yang digunakan terbatas buku tematik, evaluasi pembelajaran dilaksanakan hanya memaksimalkan memberikan tugas kepada siswa, sedangkan menurut (Salsabila et al., 2020) dalam pembelajaran jarak jauh, 
Pendas : Jurnal Ilmiah Pendidikan Dasar, ISSN Cetak : 2477-2143 ISSN Online : 2548-6950 Volume VI Nomor 01, Juni 2021

siswa harus memiliki keluasan dalam belajar dimanapun dan kapanpun. Apabila hal tersebut dibiarkan maka siswa dalam belajar akan merasa bosan. Arifin (dalam Olivia Disjayanti Fauzi, 2020) menyatakan dampak yang kurang baik dari pembelajaran daring adalah siswa merasa jenuh karena seringnya dibebani tugas yang diberikan oleh guru.

Tetapi berdasarkan hasil wawancara terhadap beberapa guru di sekolah dasar tersebut, sudah ada yang menggunakan bahan ajar dan alat evaluasi menggunakan modul. Modul tematik digunakan karena dapat membantu siswa dalam memahami pembelajaran dan membuat siswa mandiri dalam belajar. Selain itu modul digunakan sebagai alat evaluasi pembelajaran, dikarenakan di dalam modul terdapat bahan evaluasi untuk mengukur kompetensi siswa. Berdasarkan uraian yang dijelaskan di atas, fokus penelitian ini adalah mengenai pemanfaatan modul tematik sebagai alat evaluasi pembelajaran pada masa pandemi wabah covid-19. Tujuan penelitian ini adalah untuk mendeskripsikan gambaran pemanfaatan modul tematik sebagai alat evaluasi pembelajaran.

\section{B. Metode Penelitian}

Penelitian ini merupakan penelitian deskriptif kualitatif. Menurut Sukmadinata (2016) metode deskriptif kualitatif digunakan untuk mendeskripsikan kejadian ataupun fakta di lapangan benar-benar apa adanya dalam arti mendeskripsikan bagaimana pemanfaatan modul tematik sebagai alat evaluasi pembelajaran. Jenis metode deskriptif sangat tepat dilaksanakan jika tujuan penelitian hanya untuk pada pendeskripsian nyata dari faktafakta yang ada di lapangan, tidak sampai harus ada pengujian dan sebagainya. Adapun yang menjadi subjek penelitian ini adalah beberapa guru di salah satu sekolah dasar di Kota Bandung. Teknik pengumpulan data yang digunakan adalah wawancara dan dokumentasi. Menurut Sugiyono (dalam Lestari, Bahari, Budjang, 2016) wawancara digunakan sebagai teknik pengumpulan data apabila peneliti ingin melakukan studi pendahuluan untuk menemukan permasalahan yang harus diteliti, tetapi juga apabila peneliti ingin mengetahui data dari narasumber yang lebih mendalam dan nyata. Pedoman wawancara digunakan untuk memperoleh data 
Pendas : Jurnal Ilmiah Pendidikan Dasar, ISSN Cetak : 2477-2143 ISSN Online : 2548-6950 Volume VI Nomor 01, Juni 2021

atau informasi lebih rinci, sedangkan dokumentasi digunakan dalam penelitian ini untuk memperoleh data yang dalam bentuk arsip tulis maupun arsip rekaman. Teknik pengolahan dan analisis data dalam penelitian ini menggunakan model Mills and Huberman. Menurut Sugiyono (2009) aktivitas dalam analisis data menurut Miles and Huberman meliputi data reduction (reduksi data), data display (penyajian data), dan conclusion drawing/verification (penarikan kesimpulan).

\section{C.Hasil Penelitian dan Pembahasan}

Tujuan penelitian ini adalah untuk mendeskripsikan gambaran pemanfaatan modul tematik sebagai alat evaluasi pembelajaran. Teknik yang dilakukan adalah wawancara mengenai persepsi guru terhadap pemanfaatan modul tematik sebagai alat evaluasi pembelajaran saat pandemi wabah covid-19.

Pembelajaran saat ini dilakukan tidak secara tatap muka langsung di sekolah, dikarenakan sedang terjadi pandemi wabah covid-19. Hakiman (dalam Sutisno, Nurdiyanti 2020) menyatakan bahwa pembelajaran daring adalah kegiatan belajar mengajar baik antara guru dan siswa yang dilakukan jarak jauh dalam jaringan secara virtual, tanpa harus bertatap muka secara langsung. Maka dari itu dalam melaksanakan pembelajaran, guru menggunakan bahan ajar selain menggunakan buku pembelajaran. Dalam hal ini buku Tema sesuai kelas masing-masing.
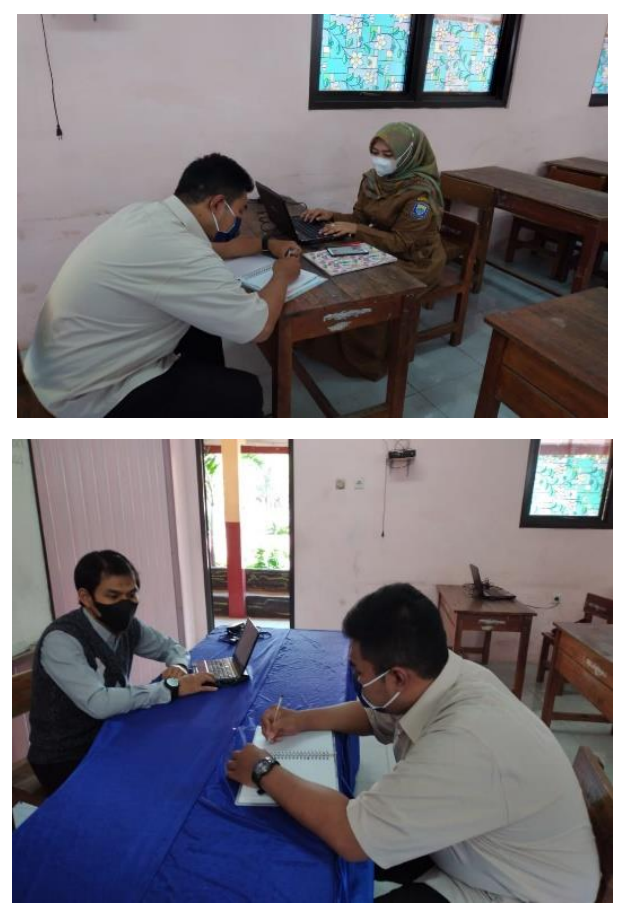

Gambar 1

Wawancara bersama Guru

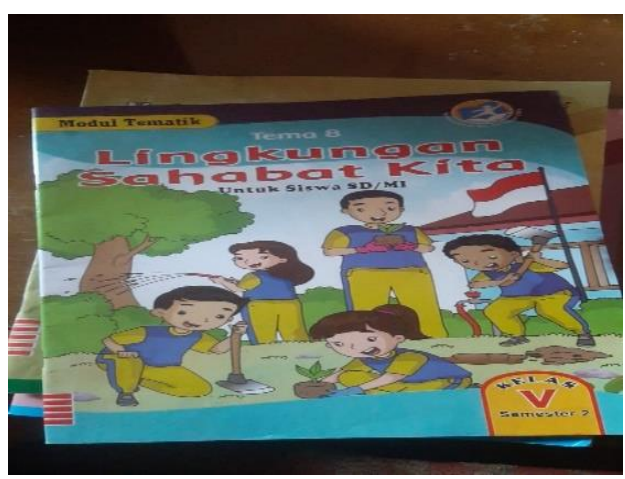

Gambar 2

Modul yang digunakan oleh guru 
Berdasarkan hasil wawancara di atas, guru menggunakan bahan ajar modul. Karena menggunakan kurikulum 2013 maka pembelajaran yang dilaksanakan adalah tematik. Modul yang digunakan adalah modul tematik pula. Menurut Prastowo (dalam Muhroji \& Yusrina, 2018) mengemukakan modul adalah bahan ajar yang telah dibuat secara tersusun dan runtut dengan memakai bahasa yang gampang dipahami oleh siswa sesuai dengan tingkatan pemahaman dan umur agar mereka bisa belajar secara mandiri. Tentunya diharapkan dengan menggunakan modul tematik, kreativitas siswa dalam belajar dapat meningkat. Karena kreativitas merupakan perantara dan upaya bagi generasi $Z$ era 4.0 belajar lebih maksimal (W. Lestari \& Barus, 2021)

Sebelum melaksanakan pembelajaran, tentu harus menyiapkan rencana pelaksanaan pemnelajaran yang biasa kita sebut RPP. Di dalam RPP tentu terdapat tujuan pembelajaran yang dipersiapkan oleh guru yang tentunya diharapkan tercapai oleh siswa. Tentunya dalam hal ini guru memiliki pengaruh seutuhnya terhadap pembelajaran yang direncakanan berdasarkan ketentuan yang berlaku.
Drake (dalam Muhroji \& Yusrina, 2018) mengemukakan salah satu faktor yang dapat memberi pengaruh pada proses belajar ialah peran dari guru dalam merencanakan pembelajaran dengan melakukan persamaan kondisi nyata yang ada serta harus berhati-hati mempertimbangkan tujuan akhir di lapangan. Guru diharapkan harus siap dan terbuka terhadap beberapa hal apa-apa yang terjadi terhadap perubahan dan memberi motivasi peserta didiknya untuk bisa mengembangkan kemampuan yang ada dalam dirinya.

Berdasarkan hasil wawancara, untuk pertanyaan nomor satu mengenai pemahaman guru terhadap modul pembelajaran tematik, dilihat dari jawabannya, maka guru sudah paham mengenai modul pembelajaran, yang merupakan bahan ajar yang telah disusun dan didalamnya terdapat materi pembelajaran dan evaluasi, tentunya disesuaikan dengan tujuan pembelajaran yang sudah direncanakan sebelumnya.

Selanjutnya untuk pertanyaan kedua mengenai apakah dalam pembelajaran, khususnya saat sekarang pembelajaran jarak jauh 
Pendas : Jurnal IImiah Pendidikan Dasar, ISSN Cetak : 2477-2143 ISSN Online : 2548-6950 Volume VI Nomor 01, Juni 2021

perlu menggunakan modul pembelajaran, dilihat dari jawaban guru maka penggunaan modul pada saat sekarang ini sangat perlu, dikarenakan sekarang pembelajaran dilaksanakan secara jarak jauh/daring diperlukan bahan ajar yang menarik dan membantu siswa memahami materi pembelajaran. Walaupun pembelajaran dilaksanakan secara jarak jauh, tetapi pembelajaran tematik harus tetap dilakukan dan modul yang digunakan juga modul tematik. Menurut Handayani (dalam Sari, Angreni, Fortuna, 2019) Modul adalah satu kesatuan sumber belajar yang telah disusun untuk membantu peserta didik dalam mencapai tujuan pembelajaran.

Modul disebut juga sebagai media atau perantara untuk belajar mandiri karena di dalam modul telah dilengkapi petunjuk untuk belajar mandiri. Artinya, peserta didik dapat melakukan kegiatan belajar tanpa kehadiran pendidik secara langsung. Berdasarkan penjelasan tersebut, maka modul pembelajaran tematik sangat perlu digunakan dalam pembelajaran, khususnya saat pembelajaran jarak jauh/daring.

Untuk pertanyaan ketiga mengenai seberapa seringkah menggunakan modul pembelajaran, terutama saat pembelajaran jarak jauh/daring. Berdasarkan jawaban wawancara dari guru, guru tersebut menjawab sering, maka dari itu modul tematik yang digunakan sebagai bahan ajar, digunakan juga sebagai bahan evaluasi pembelajaran. Dikarenakan modul didalamnya bukan hanya terdapat materi pembelajaran, tetapi terdapat juga soal-soal evaluasi. Pada pembelajaran jarak jauh/daring ini, guru tersebut sering sekali menggunakan modul, karena sebagai suplemen/bahan tambahan materi selain buku pelajaran yang sehari-hari digunakan. Karena tidak jarang ditemukan, buku pelajaran tematik masih kurang relevan dengan kompetensi yang dibutuhkan. Selain itu, terkadang buku pelajaran materi didalamnya kurang mendalam pada akhirnya siswa kurang paham terhadap materi tersebut. Maka sebagai tambahan materi pembelajaran digunakanlah modul. Merujuk kepada jawaban guru selain tambahan bahan ajar, modul digunakan sebagai bahan evaluasi pembelajaran yang biasa dilakuakukan di sekolah berjalan.

Ashari, L.H. Lestari, W. Hidayah (2016) menyatakan guru harus 
Pendas : Jurnal Ilmiah Pendidikan Dasar, ISSN Cetak : 2477-2143 ISSN Online : 2548-6950 Volume VI Nomor 01, Juni 2021

memiliki kompetensi dan keahlian dalam merancang atau menyusun suatu bahan evaluasi untuk mengetahui hasil yang ditampilkan oleh siswa, agar dapat meminimalisir kesalahan yang dibuat oleh peserta didik sebagai bahan evaluasi sehingga nantinya akan memudahkan guru untuk melakukan pembetulan terhadap kesalahan-kesalahan yang dilakukan peserta didik. Maka untuk saat ini, pemanfaatan modul tematik sebagai alat evaluasi pembelajaran sangat pas digunakan, mengingat saat ini pembelajaran dilaksanakan tidak secara tatap muka seperti biasa.

Untuk pertanyaan keempat mengenai pendapat guru tentang kelebihan dan kekurangan modul yang digunakan. Berdasarkan jawaban wawancara dari guru, mengenai kelebihan dan kekurangan dari modul memang terdapat kelebihan dan kekurangan masingmasing. Salahsatu kelebihan modul yaitu dapat memudahkan siswa untuk belajar di rumah, setidaknya ada bahan atau materi ajar yang bisa dipelajari oleh siswa-siswa selama di rumah selain menggunakan buku pelajaran tematik. Tamrongkunanan, Tanitteerapan (2020) menyatakan bahwa modul menggunakan materi pembelajaran yang diperlukan untuk memungkinkan siswa mempelajari dan menunjukkan kompetensi mereka. Selain itu menurut Prawita, Prayitno, Sugiyarto (2019) modul digunakan untuk merangsang keingintahuan siswa dan mengarah pada penalaran tingkat tinggi. Modul tentunya memiliki kekurangan, diantaranya adalah jika terlalu sering menggunakan modul, siswa akan merasa bosan belajar menggunakan modul. Maka dari itu, sebagai seorang guru harus mencari cara bagaimana pembelajaran menggunakan modul tetap berjalan dengan baik dan siswa tidak merasa bosan, dan siswa belajar secara menyenangkan sehingga siswa dapat memahami materi pembelajaran dengan baik dan motivasi belajar siswa akan meningkat. Selain itu menggunakan modul sebagai alat evaluasi, siswa tidak merasa terbebani.

Menurut Aulia, Rahmawati, Permana (2020) guru sebagai penilai, sudah sepantasnya terus untuk meninjau hasil belajar yang siswa dapatkan dalam kurun waktu tertentu. Hasil yang diperoleh tersebut merupakan tanggapan siswa terhadap proses kegiatan belajar. Tanggapan dari siswa ini akan menjadi bahan 
Pendas : Jurnal IImiah Pendidikan Dasar, ISSN Cetak : 2477-2143 ISSN Online : 2548-6950 Volume VI Nomor 01, Juni 2021

pertimbangan untuk memperbaiki dan meningkatkan proses kegiatan belajar selanjutnya yang akan datang. Dengan demikian proses belajar mengajar akan terus dapat ditingkatkan untuk memperoleh hasil yang optimal.

\section{E. Kesimpulan}

Saat ini pembelajaran dilaksanakan tidak secara tatap muka di sekolah, melainkan secara jarak jauh dikarenakan sedang terjadi pandemi wabah covid-19. Guru harus mencari cara agar pembelajaran dapat terlaksana dengan baik, termasuk evaluasi pembelajaran. Evaluasi pembelajaran harus tetap dilaksanakan, karena untuk mengukur dan menimbang sampai sejauh mana kegiatan pembelajaran apakah mencapai suatu tujuan yang telah direncanakan atau tidak, selain itu dapat kita pahami pula sebagai suatu aktivitas atau suatu proses untuk menetapkan nilai dari hal-hal yang berkaiatan dengan kegiatan pembelajaran. Kurikulum yang sekarang digunakan adalah kurikulum 2013. Pada kurikulum 2013 khususnya di sekolah dasar, pembelajaran di kelas dilaksanakan secara tematik.
Pembelajaran tematik merupakan salah satu kerangka kegiatan pembelajaran terpadu yang memakai tema untuk menggabungkan beberapa mata pelajaran sehingga dapat memberikan pengalaman belajar yang berharga bagi peserta didik. Banyak cara dan alat evaluasi yang bisa digunakan oleh guru untuk melaksanakan evaluasi pembelajaran. Salah satunya adalah dengan menggunakan modul pembelajaran. Modul pembelajaran yang dipergunakan tentunya harus sinkron dengan pembelajaran yang dilaksanakan yaitu pembelajaran tematik, dimana modul tidak hanya berisi materi pembelajaran saja tetapi terdapat bahan evaluasi yang tentunya modul dapat dimanfaatkan sebagai alat evaluasi pembelajaran. Berdasarkan hasil wawancara guru, dijelaskan bahwa guru pada saat sekarang ini sangat perlu menggunakan modul pembelajaran tematik, selain digunakan sebagai bahan ajar tambahan kepada siswa, modul juga dimanfaatkan sebagai alat evaluasi yang diberikan kepada siswanya. Maka dapat disimpulkan bahwa pada saat pembelajaran jarak jauh/daring, modul pembelajaran 
Pendas : Jurnal Ilmiah Pendidikan Dasar, ISSN Cetak : 2477-2143 ISSN Online : 2548-6950 Volume VI Nomor 01, Juni 2021

tematik dapat dimanfaatkan sebagai alat evaluasi pembelajaran.

\section{DAFTAR PUSTAKA}

Aliet Noorhayati Sutisno, D. N. (2020). Sistem Daring Pembelajaran Jarak Jauh sebagai Realisasi Merdeka Belajar di Masa Pandemi. Jurnal Riset Pedagogik, 4(1), 114-124.

Anggraini, S., \& Mering, A. (2020). Pengembangan modul pembelajaran tematik peristiwa kebangsaan masa penjajahan untuk kelas $\mathrm{v}$ sekolah dasar. Jurnal Pendidikan Dan Pembelajaran Khatulistiwa, 9(4).

Anwar, M. F. N., Ruminiati, \& Suharjo. (2017). Pengembangan Modul Pembelajaran Tematik Terpadu Berbasis Kearifan Lokal Kabupaten Sumenep Kelas IV Subtema Lingkungan Tempat Tinggalku. Jurnal Pendidikan Universitas Negeri Malang, 2(10), 1291-1297, EISSN: 2502-471X I. Arum, T. S., \& Wahyudi, W. (2016). Pengembangan Modul Pembelajaran Tematik Integratif Subtema Hubungan Makhluk Hidup Dalam Ekosistem Pendekatan Saintifik Untuk Kelas 5 Sd. Scholaria: Jurnal Pendidikan Dan Kebudayaan, 6(3), 239. https://doi.org/10.24246/j.scholari a.2016.v6.i3.p239-250

Ashari, L.H. Lestari, W. Hidayah, T. (2016). Instrumen Penilaian Unjuk Kerja Siswa Smp Kelas Viii Dengan Model
Asssessment Berbasis Android Pada Pembelajaran Penjasorkes Dalam Permainan Bola Voli. Journal of Research and Educational Research Evaluation, 5(1), 08-20. https://doi.org/10.15294/jrer.v5i1. 14876

Astuti, Y. T., Lestari, W., \& Cahyono, A. (2021). Sikap Siswa Terhadap Pembelajaran Seni Tari Di Masa Pandemi Covid-19. Jurnal Kajian Ilmiah, 21(1), 101-110. https://doi.org/10.31599/jki.v21i1. 445

Aulia, R. N., Rahmawati, R., \& Permana, D. (2020). Peranan Penting Evaluasi Pembelajaran Bahasa Di Sekolah Dasar. Jurnal BELAINDIKA, 01, 1-9.

Fuadi, Sumaryanto, T., \& Lestari, W. (2015).

Pengembangan Instrumen Penilaian Psikomotor Pembelajaran Ipa Materi Tumbuhan Hijau Berbasis Starter Experiment Approach Berwawasan Konservasi. Jere, 4(1), 1-11.

Iryanti, V. E., Lestari, W., \& Bisri, M. H. (2021). Textual Study of Sandul Performance Candigaron Village Sumowono District Semarang Regency. SSRN Electronic Journal.

https://doi.org/10.2139/ssrn.3800 633

Lestari, J. W., Bahari, Y., \& Budjang, G. (2016). Implementasi Kompetensi Sosial Guru Sosiologi Dalam Berkomunikasi Dengan Peserta Didik Di MAN 1 Pontianak. Jurnal Pendidikan Dan Pembelajaran Khatulistiwa, 
5(12), 1-13.

Lestari, W., \& Barus, S. S. (2021). BUDHE' CENTIL CROSS GENDER DANCE HORI ART \&amp; $\quad$ ENTERTAINMENT YOGYAKARTA AS BREAKTHROUGH FORMS OF THE Z GENERATION. SSRN Electronic Journal. https://doi.org/10.2139/ssrn.3800 610

M.Panji Wahyu Mukti, W. L. (2020).

PELAKSANAAN EVALUASI

PEMBELAJARAN SENI BUDAYA DI SMP 1 JEKULO KUDUS PADA MASA PANDEMI COVID-19. Jurnal Pendidikan Seni, VI(1). Jurnal Pendidikan Seni

Muhroji, M., \& Yusrina, H. (2018). Penggunaan Modul Pada Pembelajaran Tematik Di Sdn 1 Jimbung Klaten. Profesi Pendidikan Dasar, 1(1), 1. https://doi.org/10.23917/ppd.v1i1 .6457

Nugroho, M. A., Florentinusa, T. S., \& Lestari, W.

(2020).

Pengembangan Instrumen

Penilaian Materi Musik Ansambel Berbasis Android bagi Siswa SMP. Seminar Nasional Pascasarjana, 2019, 207-215.

Olivia Disjayanti Fauzi, S. B. S. (2020). PROFIL PERAN GURU SD DALAM KEGIATAN BELAJAR MENGAJAR DARI RUMAH DI MASA PANDEMI COVID-19. Pendas : Jurnal IImiah Pendidikan Dasar, V(2), 160167.

Prawita, W., Prayitno, B. A., \& Sugiyarto. (2019). Effectiveness of a generative learning-based biology module to improve the analytical thinking skills of the students with high and low reading motivation. International Journal of Instruction, 12(1), 1459-1476.

https://doi.org/10.29333/iji.2019.1 2193a

Purnomo, H., \& Wulandari, I. (2019). Pengembangan Bahan Ajar Evaluasi Pembelajaran Untuk Pendidikan Guru Sekolah Dasar Universitas Kuningan. JURNAL PAJAR (Pendidikan Dan Pengajaran), 3(6), 1204. https://doi.org/10.33578/pjr.v3i6. 7878

Riwanti, R., \& Hidayati, A. (2019). Pengembangan Modul Pembelajaran Tematik Berbasis Pendidikan Karakter Di Kelas V Sekolah Dasar. Jurnal Basicedu, 3(2), 572-581. https://doi.org/10.31004/basicedu .v3i2.41

Rona Taula Sari, Siska Angreni, R. A. F. (2019). PENGEMBANGAN MODUL PEMBELAJARAN IPA BERBASIS PENDEKATAN KONSTRUKTIVISME UNTUK KELAS V SD. Jurnal Pembelajaran Biologi, 8, 89-93. https://jurnal.uns.ac.id/pdg/article /view/34725

Salsabila, R., Murtono, M., \& Purbasari, I. (2020). Analisis Proses Dan Dampak Pembelajaran Daring Di Sd AlIslam Pengkol Jepara Pada Masa Pandemi Covid-19 Tahun 2020. Pendas: Jurnal IImiah Pendidikan Dasar, V(2), 151- 
159.

https://doi.org/10.23969/jp.v5i2.3

422

Sofiyatunningtiyas, T. N., Nugroho, A., Muslim, A., \& Purwokerto, U. M. (2020). Implementasi pembelajaran tematik kurikulum 2013 dalam pembentukan karakter siswa. Jurnal Riset Pendidikan Dasar, 15-23.

Sugiyono (2009). Metode Penelitian

Kuantitatif, Kualitatif dan $R \& D$.

Bandung: Alfabeta

Sukmadinata, Syaodih, N. (2016).

Metode Penelitian Pendidikan.

Bandung: PT. Remaja

Rosdakarya

Tanapon Tamrongkunanan, T. T. (2020). Development of Required Knowledge and Skills among Students through Applied Learning Modules. International Journal of Instruction, 13(4), 695714. 